\title{
Erratum to: 2D maneuverable robotic fish propelled by multiple ionic polymer-metal composite artificial fins
}

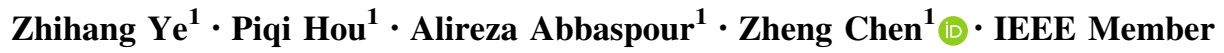

Published online: 14 August 2017

(C) Springer Nature Singapore Pte Ltd. 2017

\section{Erratum to: Int J Intell Robot Appl (2017) \\ 1:195-208 \\ DOI 10.1007/s41315-017-0019-5}

The original version of this article unfortunately contained a mistake.

Alireza Abbaspour was not listed among the authors.

2D maneuverable robotic fish propelled by multiple ionic polymer-metal composite artificial fins

Zhihang $\mathrm{Ye}^{1}$. Piqi Hou ${ }^{1}$. Alireza Abbaspour ${ }^{1} \cdot$ Zheng Chen $^{1}$. IEEE Member

The online version of the original article can be found under doi:10.1007/s41315-017-0019-5.

\section{Zheng Chen}

zheng.chen@wichita.edu

1 Department of Electrical Engineering and Computer Science, Wichita State University, Wichita, KS 67260-0083, USA

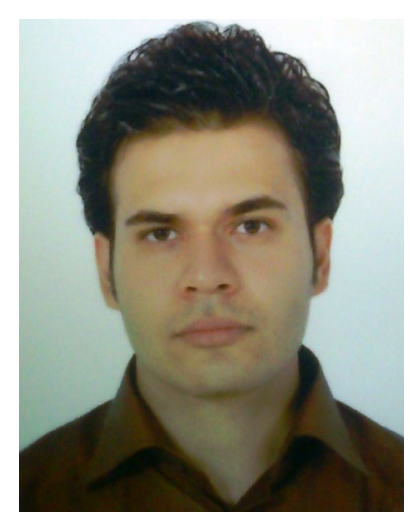

Alireza Abbaspour was born in Mashhad, Iran, in 1988 and received his B.Sc. degree in Control Engineering from Sadjad University of Technology, Iran, in 2011, and M.Sc. degree in Guidance and Control Engineering from Maleke Ashtar University of Technology (MUT), Iran in 2013. His current research interests are dynamic modeling, nonlinear control, fault detection, and artificial intelligence. He was a graduate student in the Department of Electrical Engineering and Computer Science at Wichita State University when he worked for this paper. Currently, he is pursuing his Ph.D. degree in Control Engineering at Florida International University, Miami, Florida, USA. Email: alireza.abaspour@gmail.com. 